Article

\title{
Comparison of Atmospheric Travel Distances of Several PAHs Calculated by Two Fate and Transport Models (The Tool and ELPOS) with Experimental Values Derived from a Peat Bog Transect
}

\author{
Sabine Thuens ${ }^{1}$, Christian Blodau ${ }^{1,2}$, Frank Wania ${ }^{3}$ and Michael Radke ${ }^{1,4, *}$ \\ 1 Department of Hydrology, BayCEER, University of Bayreuth, D-95440 Bayreuth, Germany; \\ E-Mails: sabine.thuens@gmail.com (S.T.); c.blodau@uni-muenster.de (C.B.) \\ 2 Hydrology Group, Institute of Landscape Ecology, University of Münster, D-48149 Münster, Germany \\ 3 Department of Physical and Environmental Sciences, University of Toronto Scarborough, Toronto, \\ ON M1C1A4, Canada; E-Mail: frank.wania@utoronto.ca \\ 4 Department of Applied Environmental Science (ITM), Stockholm University, \\ 10691 Stockholm, Sweden \\ * Author to whom correspondence should be addressed; E-Mail: michael.radke@itm.su.se; \\ Tel.: +46-8674-7136.
}

Received: 19 December 2013; in revised form: 17 April 2014 / Accepted: 18 April 2014 / Published: 23 May 2014

\begin{abstract}
Multimedia fate and transport models are used to evaluate the long range transport potential (LRTP) of organic pollutants, often by calculating their characteristic travel distance (CTD). We calculated the CTD of several polycyclic aromatic hydrocarbons

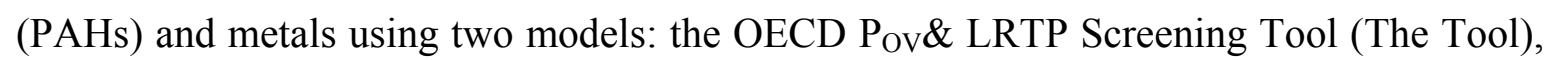
and ELPOS. The absolute CTDs of PAHs estimated with the two models agree reasonably well for predominantly particle-bound congeners, while discrepancies are observed for more volatile congeners. We test the performance of the models by comparing the relative ranking of CTDs with the one of experimentally determined travel distances (ETDs). ETDs were estimated from historical deposition rates of pollutants to peat bogs in Eastern Canada. CTDs and ETDs of PAHs indicate a low LRTP. To eliminate the high influence on specific model assumptions and to emphasize the difference between the travel distances of single PAHs, ETDs and CTDs were analyzed relative to the travel distances of particle-bound compounds. The ETDs determined for PAHs, $\mathrm{Cu}$, and $\mathrm{Zn}$ ranged from 173 to $321 \mathrm{~km}$ with relative uncertainties between $26 \%$ and $46 \%$. The ETDs of two metals were shorter than
\end{abstract}


those of the PAHs. For particle-bound PAHs the relative ETDs and CTDs were similar, while they differed for Chrysene.

Keywords: long-range transport potential; PAHs; characteristic travel distance; transport modeling

\section{Introduction}

In the atmosphere, some semi-volatile organic chemicals (SVOCs) are transported long distances before being deposited [1]. To evaluate whether the environmental release of a man-made chemical may need to be curtailed through international agreements like the Stockholm Convention on Persistent Organic Pollutants, a number of compound-specific hazard indicators is often determined and compared with threshold criteria [2]. One of these indicators is a contaminant's spatial range or long-range transport potential (LRTP) [3], which can be characterized by the characteristic travel distance (CTD) [4]. The CTD is defined as the distance from a source where the concentration of a chemical is reduced by $63 \%$. A fraction of the chemical can travel a multiple of the CTD.

Several models such as the "Environmental Long-range Transport and Persistence of Organic Substances Model" (ELPOS) [5] and the POV\& LRTP Screening Tool ("The Tool") [6] have been developed and applied to estimate the CTD of various chemicals. Both are steady-state fugacity models that estimate the CTD based on a compound's equilibrium partitioning properties, transformation rates in environmental media, and environmental properties, such as wind speed. The Tool has been designed to be as basic as possible while including all essential information [7], whereas ELPOS is more complex and includes more compartments and additional options. Both models can be used to assess a chemical's LRTP by comparing and ranking its CTD against that of identified persistent organic pollutants [8]. By comparing the results of various models the influence of different model assumptions and design features can become apparent [9]. Both models are not intended to simulate real world conditions. However, to increase confidence in the results and to identify possible model failure, their estimates should qualitatively agree with empirically derived data. To date, experimental data that facilitate the evaluation of these models with respect to the estimated CTDs are sparse [10,11].

Polycyclic aromatic hydrocarbons (PAHs) are emitted by natural combustion processes, such as forest fires, but anthropogenic emissions dominate, specifically through the incomplete combustion of carbon-based fuels. They undergo atmospheric long-range transport [12]. Their saturation vapor pressures and, therefore, their gas/particle partitioning characteristics span a wide range [13]. Based on their gas/particle partitioning behavior in the rural atmosphere of Eastern Canada, PAHs can be divided in three groups [14]: g-PAHs that are almost exclusively present in the gas phase (e.g., phenanthrene (Phen) and fluoranthene (Flt)), c-PAHs (c for changing partitioning behavior) that are present in the gas phase in summer and particle-bound in winter (e.g., benzo[a]anthracene (B[a]A) and chrysene (Chry), and p-PAHs that are almost exclusively particle-bound all year long (e.g., benzo[b+k]fluoranthene $(\mathrm{B}[\mathrm{b}+\mathrm{k}] \mathrm{F})$, benzo[a]pyrene $(\mathrm{B}[\mathrm{a}] \mathrm{P})$, and indeno[1,2,3-cd]pyrene(Ind)). To empirically determine LRTP, measurements at variable distances from a distinct contaminant source generating measurable concentrations have to be done [5]. The rates of decline of 
log-transformed concentrations over large latitudinal gradients in North America have been used to determine empirical travel distance (ETDs) of pesticide chemicals [10,11]. A general problem with such an approach is that additional sources along a long transect may affect the results. Moreover, substantial changes in temperature and precipitation along latitudinal gradients might complicate data interpretation due to the temperature dependence of gas/particle partitioning and atmospheric reaction rates and the dependence of deposition rates on the magnitude and temporal variability of precipitation. This study aimed at using a shorter, regional transect downwind of a dominant point source to determine ETDs of a range of PAHs, which were then used to evaluate the CTDs derived with The Tool and ELPOS.

CTDs not only scale linearly with wind speed, but also rely on several simplifying and generalizing assumptions and are based on a simplistic representation of the environment. Therefore, absolute values given by the models are not directly comparable to ETDs. To facilitate a comparison, both ETDs and CTDs were normalized to those of inert aerosol particles and Ind. Therefore, we compare relative rather than absolute values. Because most metals, including zinc $(\mathrm{Zn})$ and copper $(\mathrm{Cu})$, undergo atmospheric transport exclusively bound to particles [15] and are not degraded in the atmosphere, they can be used to estimate the atmospheric transport distance of particles. As Ind is also mainly bound to particles, we used it as a second proxy for particle-bound substances when normalizing travel distances.

We selected four ombrotrophic bogs along a $\sim 400 \mathrm{~km}$ transect downwind of a large mining and smelting operation in Eastern Canada (Greater Sudbury area, Ontario; Figure 1) to derive the temporal trend of atmospheric deposition of PAHs, $\mathrm{Zn}$ and $\mathrm{Cu}$. The smelters in the Greater Sudbury area have been a known source of air pollution, especially for copper and sulphur-based acid precipitation, to the surrounding area for the last century [16]. Smelters emit PAHs and metals to the atmosphere as a consequence of wood or coal firing and roasting processes [15,17,18]. Ombrotrophic peat bogs have previously been used as archives of the atmospheric deposition of several classes of organic and inorganic contaminants [19-22]. The combination of continuous growth and limited bioturbation with atmospheric wet and dry deposition as the only source of contaminants makes them well suited to derive the historical atmospheric deposition trend of non-polar contaminants. Historical depositions were used here as they represent a long-term average. More importantly, the Greater Sudbury area was the dominant regional source in the past, whereas today there are many potential sources of PAHs. As deposition rates of pollutants correlate to their air concentrations [23], the decline of deposition rates over distance can be used to derive the ETD.

Figure 1. Locations of sampled peat bogs in Ontario, Canada.

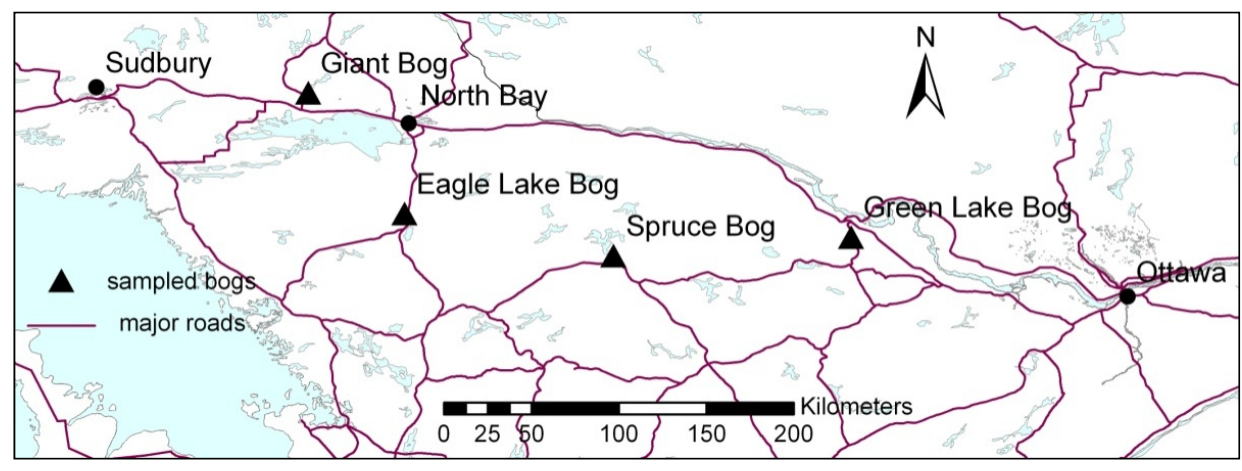




\section{Methods}

\subsection{Sampling and Analysis}

Peat cores were sampled at four bogs located downwind of the Greater Sudbury area (Canada; Figure 1) in summer 2008. Coordinates of the sampling locations are given in Table S1 in the Supplementary Material. At each site, three peat cores were sampled in hollows with a box corer and cut into $5 \mathrm{~cm}$ segments in the field. Samples were transported to the laboratory, frozen, freeze dried, and milled to a fine powder. For determination of PAHs, recovery standards (mixture of 7 deuterium-substituted PAHs) were added to $5 \mathrm{~g}$ (dry weight) of sample before extraction by accelerated solvent extraction with hexane. Extracts were purified by column chromatography (5 g silica, $3 \mathrm{~g}$ alox 15\% deactivated) followed by size exclusion chromatography. The concentrations of 12 PAHs (10 EPA-PAHs: phenanthrene, fluoranthene, pyrene (Pyr), benzo[a]anthracene, chrysene, benzo $[b]$ fluoranthene, benzo $[k]$ fluoranthene, benzo $[a]$ pyrene, indeno[1,2,3-cd]pyrene, and benzo[ghi]perylene $(\mathrm{B}[$ ghi $] \mathrm{P})$, and additionally benzo[e]pyrene $(\mathrm{B}[\mathrm{e}] \mathrm{P})$, and benzo[j]fluoranthene $(\mathrm{B}[\mathrm{j}] \mathrm{F})$ ) were determined as described in [22]. Due to the incomplete chromatographic separation of $\mathrm{B}[\mathrm{b}] \mathrm{F}$ and $\mathrm{B}[\mathrm{k}] \mathrm{F}$, the sum of the compounds is reported as $\mathrm{B}[\mathrm{b}+\mathrm{k}] \mathrm{F}$. Because these isomers have similar physico-chemical properties (less than $10 \%$ difference) $[24]$, the ETD of $\mathrm{B}[\mathrm{b}+\mathrm{k}] \mathrm{F}$ was compared to the CTD of B[b]F. A mass of $200 \mathrm{mg}$ of the milled peat samples was digested by a microwave assisted acid dissolution technique [25] and $\mathrm{Cu}$ and $\mathrm{Zn}$ were analyzed by ICP-MS. The peat cores were dated using ${ }^{210} \mathrm{~Pb}\left(t_{1 / 2}=22.26\right.$ years $)$ by applying the constant rate of supply model [26].

\subsection{Calculation of ETDs}

The temporal resolution that can be achieved with peat cores is relatively low [22]. Individual segments of $5 \mathrm{~cm}$ span periods of 20 to 30 years. In contrast to previous work [20] we did not calculate 10-year-averaged deposition rates, as this procedure might reduce the absolute magnitude of reconstructed deposition rates. Instead, we based our analyses on the segments showing the maximum PAH deposition rate. Such maxima have previously been suggested as chrono-stratigraphic markers in peat profiles by Turetsky et al. [27]. In all peat cores PAH deposition rates peaked around 1880-1930, coinciding with the onset of intensive smelter operations in Sudbury. At that time, the smelters were one of the main sources of PAHs in the study region as the population was small and other sources, such as traffic, were not that relevant yet.

For each compound, the maximum deposition rates from each of the three replicate cores per bog were ln-transformed and linearly regressed against the distance of the sampling site from the Inco Superstack in Sudbury. In cases where the decline of the deposition rates was significant $(p<0.1)$ the negative reciprocal of the slope $m\left(\mathrm{~km}^{-1}\right)$ of the regression line corresponds to the ETD for the respective compound, and the ETD consequently corresponds to the distance where the air concentration of a compound declined by $63 \%$ (1/e). The error of the slope of the regression was used to estimate the uncertainty of the ETDs. The software package R [28] was used for these calculations.

Wind speed is an important parameter constraining atmospheric transport of contaminants, but reliable data on average wind speed are difficult to obtain for large areas and longer periods. 
To facilitate the comparison of measured and calculated transport distances, we eliminated this source of uncertainty by normalizing the PAH transport distances to those of aerosol particles. As a proxy for the transport distance of particles, we used the average transport distance of the metals $\mathrm{Cu}$ and $\mathrm{Zn}$ or the PAH Ind. Subsequently, we refer to these normalized distance as $r_{\text {metal }}$-ETD and $r_{\text {Ind }}$-ETD.

\subsection{Model Description}

The Tool and ELPOS have both been designed to distinguish between chemicals with low and high LRTP [29]. They are steady state fugacity models (level III, no equilibrium, inter-compartment transport [30]) that assess the environmental hazard of organic chemicals using the metrics of CTD and overall persistence $\left(\mathrm{P}_{\mathrm{OV}}\right)$ under different emission scenarios [7]. With only three generic compartments (air, soil and water), The Tool requires five input parameters for each compound: the air-water $\left(K_{\mathrm{AW}}\right)$ and octanol-water $\left(K_{\mathrm{OW}}\right)$ partition coefficients as well as degradation half-lives $\left(t_{1 / 2}\right)$ in air, water, and soil. A Monte Carlo (MC) analysis routine estimates the $95 \%$ confidence interval of $\mathrm{P}_{\mathrm{OV}}$ and CTD. In this study we used dispersion factors of 5 and 10 for partition coefficients and half-lives, respectively, comparable to the factors of 3 and 10 used previously [8]. ELPOS (Version 2.2) has eight compartments: air, water, sediment, four soil compartments (natural, agricultural, industrial, urban), and plants [5], necessitating seven chemical input parameters: $K_{\mathrm{AW}}, K_{\mathrm{OW}}$ and the organic carbon partition coefficient $\left(K_{\mathrm{OC}}\right)$; as well as $t_{1 / 2}$ in air, water, soil, and sediment. Instead of estimating the $K_{\mathrm{OC}}$ from $K_{\mathrm{OW}}$, we used the option to supply it directly as well as the $K_{\mathrm{OA}}$-approach to estimate the particle-bound fraction in air.

In addition to the CTD, both models also provide the fraction of a compound bound to particles in air as output information. As degradation rates for pollutants bound to particles are generally slow compared to the gas phase [31] and reliable estimates are difficult to obtain, both models assume that compounds associated with particles do not degrade [29].

Some of the default environmental input parameters of both models were adjusted to reflect the characteristics of Southern Ontario (fraction of model region covered by water $=10 \%$, average water depth $=10 \mathrm{~m}$, yearly average precipitation $=1008 \mathrm{~mm}$, average wind speed $=13.1 \mathrm{~km} \cdot \mathrm{h}^{-1}$ taken from Canadian Climate Normals for North Bay-A, WMO ID: 71731, period 1971-2000 [32]). More detailed information on the model input parameters is provided as Supporting Material (Tables $\mathrm{S} 2$ and S3). Three temperature scenarios reflect the annual average $\left(4^{\circ} \mathrm{C}\right)$, summer $\left(13^{\circ} \mathrm{C}\right)$, and winter (limited to $0{ }^{\circ} \mathrm{C}$ as partition behavior to frozen compartments might differ and is not taken into account by the model calculations) conditions in Southern Ontario [32].

Partition coefficients $\left(K_{\mathrm{OW}}\right.$ and $\left.K_{\mathrm{AW}}\right)$ at $25{ }^{\circ} \mathrm{C}$ for the PAHs were taken from Ma et al. [24]. The $K_{\mathrm{OC}}$ values at $25{ }^{\circ} \mathrm{C}$ were estimated using a poly-parameter linear free energy relationship (pp-LFER) [33] and solute descriptors from Absolv online [34]. While ELPOS has a built-in routine to adjust these coefficients to a user-supplied temperature, The Tool requires the user to supply temperature-adjusted input information. The $K_{\mathrm{AW}}$ values were adjusted using the temperature dependent pp-LFERs from Goss et al. [35]; $K_{\mathrm{OA}}$ values from Ma et al. [24] were adjusted using enthalpies of vaporization, derived as described in Goss and Schwarzenbach [36]. Finally, temperature-adjusted $K_{\mathrm{OW}}$ were obtained as the product of $K_{\mathrm{AW}}$ and $K_{\mathrm{OA}}$. We preferred predicted values since consistency between the properties of different PAHs is more important than accuracy of 
single properties. Degradation half-lives in air reflecting the reaction of PAHs in the gas phase with hydroxyl radicals were estimated with the Atmospheric Oxidation Program (AOPWIN v1.92) using default settings for a 12-h day as done by others [10,11]. However, AOPWIN does not estimate activation energies, which are necessary to calculate degradation rate constants at different temperatures [29]. Temperature dependent rate constants for the reaction with hydroxyl radicals are only available for Phen and Flt [37]. The temperature dependence is so small that in case of The Tool degradation of all PAHs in air can be assumed to not depend on temperature [29]. However, the variability in daytime length and $\mathrm{OH}$ radical concentration with season was taken into account. Therefore we used the averaged $\mathrm{OH}$ concentrations calculated for the atmospheric boundary layer (1000 and $900 \mathrm{hPa}$ ) by Spivakovsky et al. [38]. Average daylight hours were taken from [39]. Degradation half-lives in water, soil and sediment were estimated with EPISuite v4.0 [40] and retrieved through the Level III Fugacity Model implemented in this software. In ELPOS degradation rates are temperature adjusted by an implemented routine. By setting the temperature to $25{ }^{\circ} \mathrm{C}$ and using the manually adjusted values calculated for the Tool the implemented temperature adjustment was bypassed.

Whereas the two models were not designed to estimate CTDs of metals, it is possible to use them to calculate the CTD of exclusively particle-bound substances. As the metals for which we were able to determine ETDs $(\mathrm{Cu}, \mathrm{Zn})$ do not partition into the gas phase, they can be considered surrogates for particle-bound organic contaminants. The CTDs for such particle-bound contaminants was estimated by assigning partition coefficients that ensured almost exclusive partitioning to particles $\left(\log K_{\mathrm{OW}}=10, \log K_{\mathrm{AW}}=-9\right.$, yielding $\log K_{\mathrm{OA}}$ of 19$)$. In addition, we assigned a very long environmental half-life $\left(t_{1 / 2}=10^{10} \mathrm{~h}\right)$. Additional information on this choice of parameters is available as Supporting Material (Figure S1). All model input parameters are listed in Tables S4 and S5. Table S6 summarizes the temperature-adjusted chemical properties. As for the ETDs, relative CTDs were calculated by normalizing the CTDs of the PAHs to the CTD of Ind ( $\mathrm{r}_{\text {Ind }}-\mathrm{CTD}$ ) and of exclusively particle-bound compounds ( $\mathrm{r}_{\text {particle-CTD). }}$

The sensitivity of the CTD to changes in input values was tested by a sensitivity analysis as described in Wania and Dugani [41]. A sensitivity of 1 indicates proportional changes of input values and CTDs. A sensitivity $<1$ indicates that the CTD does not respond linearly to changes of the input value. We analyzed the sensitivity of temperature (ELPOS only), wind speed, height of the air compartment, aerosol deposition velocity, precipitation rate, rain scavenging ratio, half-life times in all compartments, and partition coefficients for the $4{ }^{\circ} \mathrm{C}$ scenario by varying the values by $10 \%$.

\section{Results and Discussion}

\subsection{Empirically Determined Travel Distances}

The maximum deposition of PAHs and the two metals was measured in peat segments dated to the period 1880-1930 (Figure S2 in Supporting Material, data given in Table S7). The increase in deposition around 1880 coincides with the onset of intense smelting operations in Sudbury. In most peat profiles, we observed declining deposition rates from 1920 onwards, when blast furnaces and roast yards were replaced by multi-hearth roasters and reverberatory furnaces for smelting [42]. More detailed data and interpretation is available in Thuens et al. [22]. 
The maximum deposition rates of Chry, $\mathrm{B}[\mathrm{b}+\mathrm{k}] \mathrm{F}, \mathrm{B}[\mathrm{a}] \mathrm{P}$ and Ind, as well as of $\mathrm{Cu}$ and $\mathrm{Zn}$ declined exponentially $(p<0.1)$ with distance from Sudbury (Figure 2). Together with the prevailing westerly winds, this finding is a powerful indication that the dominant source of atmospheric contamination to the studied bogs during the time of peak deposition was located in the Greater Sudbury area. For Phen, Flt, Pyr, and B[a]A, this decline was not significant (see Figure S3 in Supporting Material); for $\mathrm{B}[$ ghi $] \mathrm{P}, \mathrm{B}[\mathrm{e}] \mathrm{P}$, and $\mathrm{B}[\mathrm{j}] \mathrm{P}$ no ETD could be calculated, as concentrations were below the level of quantification in several samples. Therefore, these compounds are not considered in the following discussion.

The ETDs of PAHs, $\mathrm{Cu}$, and $\mathrm{Zn}$ are shown in Table 1. They range from 173 to $321 \mathrm{~km}$ with relative uncertainties between $26 \%$ and $46 \%$. The ETDs of the two metals were shorter than those of the PAHs. The discrepancy between the two metal ETDs reflects the overall uncertainty of our approach. Their

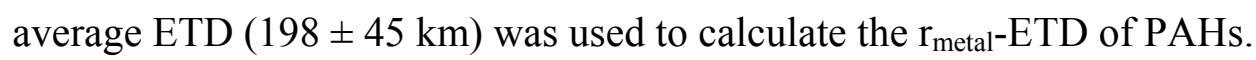

Table 1. Empirical travel distances (ETDs) with standard error (SE), significance level $(p)$, coefficient of determination $\left(R^{2}\right)$, and relative experimentally determined travel distances ( $r_{\text {metal }}$-ETD and $r_{\text {Ind }}$-ETD) with SE.

\begin{tabular}{ccccccccc}
\hline & ETD $(\mathbf{k m})$ & $\mathbf{S E}(\mathbf{k m})$ & $\boldsymbol{p}$ & $\boldsymbol{R}^{\mathbf{2}}$ & $\mathbf{r}_{\text {metal }}$-ETD (-) & SE (-) & $\mathbf{r}_{\text {Ind }}$-ETD (-) & SE (-) \\
\hline Phen & $\mathrm{n} / \mathrm{a} *$ & & 0.222 & 0.14 & $\mathrm{n} / \mathrm{a} *$ & & & \\
Flt & $\mathrm{n} / \mathrm{a}$ & & 0.195 & 0.16 & $\mathrm{n} / \mathrm{a}$ & & & \\
Pyr & $\mathrm{n} / \mathrm{a}$ & & 0.402 & 0.07 & $\mathrm{n} / \mathrm{a}$ & & & \\
$\mathrm{B}[\mathrm{a}] \mathrm{A}$ & $\mathrm{n} / \mathrm{a}$ & & 0.119 & 0.23 & $\mathrm{n} / \mathrm{a}$ & & & \\
Chry & 292 & 119 & 0.034 & 0.37 & 1.47 & 0.54 & 0.94 & 0.56 \\
$\mathrm{~B}[\mathrm{~b}+\mathrm{k}] \mathrm{F}$ & 281 & 74 & 0.003 & 0.59 & 1.42 & 0.44 & 0.91 & 0.46 \\
$\mathrm{~B}[\mathrm{a}] \mathrm{P}$ & 321 & 148 & 0.055 & 0.32 & 1.62 & 0.58 & 1.04 & 0.60 \\
$\mathrm{Ind}$ & 310 & 119 & 0.026 & 0.41 & 1.57 & 0.52 & & \\
$\mathrm{Cu}$ & 173 & 31 & 0.0002 & 0.76 & - & & & \\
Zn & 222 & 56 & 0.003 & 0.61 & - & & & \\
\hline
\end{tabular}

Note: * n/a: value not available as correlation of deposition rate with distance was not significant.

Figure 2. Average maximum deposition rates of (A) PAHs and (B) metals as a function of distance from the Greater Sudbury source area. The error bars represent the standard deviation of the three replicate peat cores.
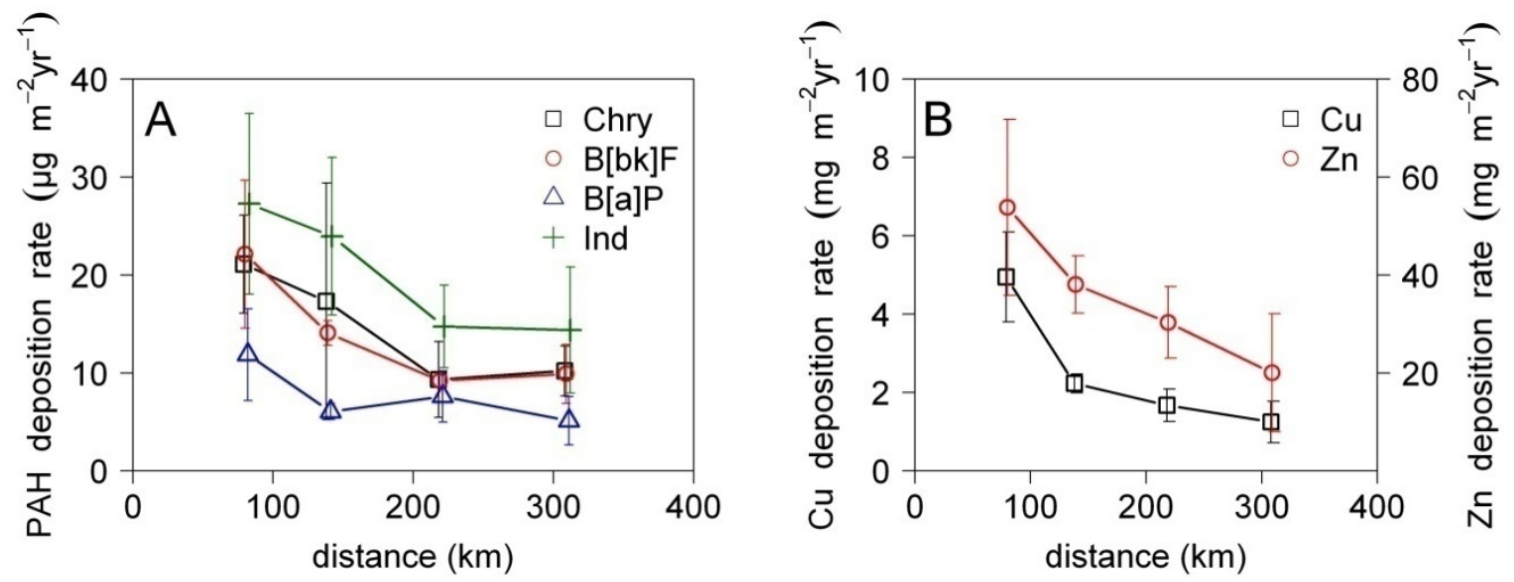
Using data from several studies reporting metal deposition rates at variable distances from smelters [43-45], we calculated ETDs for $\mathrm{Cu}, \mathrm{Zn}, \mathrm{Pb}$ and $\mathrm{Ni}$ between $21 \mathrm{~km}$ and $67 \mathrm{~km}$. Average uncertainty was $17 \%$ (Table S8 in Supporting Material). These ETDs are considerably lower than those we have obtained here. In these previous studies, samples were taken within a distance of up to $125 \mathrm{~km}$ from the smelters. It is known that metals such as $\mathrm{Ni}, \mathrm{Zn}$, and $\mathrm{Cu}$ are associated with both smaller and larger aerosol particles in the atmosphere [46]. As larger particles are deposited more rapidly than smaller ones [47], large particles will dominate the deposition close to the emission source, while fine particles will be deposited at longer distances. This might cause divergent ETDs depending on the spatial scale and resolution of a particular study: the apparent ETD may be short in the immediate vicinity of the smelter, where deposition of coarse particles dominates, and long at larger distances, where mainly fine particles are deposited. This interpretation would explain the longer metal ETDs observed in our study, as the distances of the sites we analyzed are outside the range influenced by larger particles. As coarse particles are not subject to atmospheric long-range transport, we conclude that the metal ETDs determined in this study are more representative of the travel distances of the particles relevant for long-range transport of organic chemicals.

\subsection{Characteristic Travel Distance}

\subsubsection{The Tool}

With the default settings of The Tool, CTDs up to $2860 \mathrm{~km}$ were calculated for particles at $4{ }^{\circ} \mathrm{C}$. After adjusting the settings and input parameters to the specific conditions in the study region the estimated CTDs were lower by a factor of 7.5. This reduction is mainly caused by changes in the partition coefficients and changes in size of the individual compartments, while wind speed contributed to a minor extent. The $95 \%$ confidence intervals of the absolute CTDs were larger for g-PAHs than p-PAHs (e.g., factor of 46 for B[a]A, 40 for Phen, 9 for Chry and 2 to 3 for the p-PAHs) indicating a higher uncertainty of the CTD for $\mathrm{B}[\mathrm{a}] \mathrm{A}$ and the g-PAHs. Details are summarized in Table S9 (Supporting Material). The confidence intervals cover ranges from almost 10 to $5500 \mathrm{~km}$, indicating the high uncertainty of the model results.

Using The Tool, the CTD of particles was longer than the CTDs of the PAHs except for the CTD of Phen and Flt in winter. Consequently, most $r_{\text {particle}}-C$ TDs are $<1$ (Figure 3A). The CTD for Phen in winter was greater than all other CTDs by a factor of 4 . The p-PAHs had almost the same CTD as the particles, while those of $\mathrm{g}$ - and c-PAHs were substantially shorter. B[a]A had the shortest CTD. As the CTD of Ind was almost the same as the one of particles, $r_{\text {Ind }}$-CTDs were equal to the $r_{\text {particle}}$-CTDs.

The CTD of particles was identical for the three temperature scenarios. The CTDs of all PAHs decreased with increasing temperature, which can be attributed to a higher proportion of these compounds being in the gas phase at higher temperatures and the gas phase degradation half-lives in air being shorter because of longer days and higher $\mathrm{OH}$ concentrations in summer, when temperatures are higher. Conversely, the high CTD of Phen and Flt for the $0{ }^{\circ} \mathrm{C}$ scenario is caused by the long half-lives in air, which are a result of short days and low $\mathrm{OH}$ concentrations in winter. The Tool predicted the c-PAHs to be mainly particle-bound in winter and equally distributed between gas and 
particle phase in summer $\left(13^{\circ} \mathrm{C}\right)$, whereas the p-PAHs were almost exclusively particle-bound at all temperatures. This is in good agreement with measured gas-particle distributions [14].

The CTDs of all studied compounds were directly proportional to wind speed (sensitivity of 1, Figure 3B). For the g-PAHs, half-life in air was the only other parameter with high sensitivity. The CTDs of the less volatile PAHs were sensitive to the particle deposition velocity, the precipitation rate, and the height of the air compartment while the sensitivity to the half-life in air was lower (Figure 3B). This finding reflects the importance of the removal of c- and p-PAHs from the atmosphere by dry or wet deposition.

\subsubsection{ELPOS}

With default settings, CTDs from $295 \mathrm{~km}$ (Flt) to $700 \mathrm{~km}$ were calculated with ELPOS (particles, $4{ }^{\circ} \mathrm{C}$ ). With region-specific settings, CTDs between $142 \mathrm{~km}(\mathrm{~B}[\mathrm{a}] \mathrm{A})$ and $517 \mathrm{~km}$ (particles) were estimated for the annual average temperature of $4{ }^{\circ} \mathrm{C}$ (Table S10 in Supporting Material). This reduction was caused by a lower height of the air compartment and a higher precipitation in the study area. The $\mathrm{r}_{\text {particle}}$-CTDs for all PAHs covered the range from 0.10 to 4.6 under the three temperature scenarios (Figure 3C). B[a]A had the shortest $r_{\text {particle}}$-CTD due to its high degradation rate in air in summer, Phen had the longest in winter.

The temperature dependence of the chemical properties was substantial, e.g., $K_{\mathrm{AW}}$ were up to $90 \%$ lower and half-lives $200 \%$ longer in the winter scenario compared to summer (Table S6). This effect had a high impact on the calculated CTDs. With rising temperatures, the CTDs of all PAHs diminished due to increased reactive loss from air. The relation between temperature and CTD was almost linear, with coefficients of determination for the regression of CTD against temperature $>0.98$ (Figure 3). The effect of temperature was largest for B[a]A and $\mathrm{B}[\mathrm{a}] \mathrm{P}$ and the CTD in winter double that in summer.

The particle-bound fraction of B[a]P and Ind estimated by ELPOS was less than 100\% (given in Table S10 in Supporting Material) for all temperature scenarios and decreased with increasing temperature. This contrasted with measurements in Southern Ontario [14] where these PAH could not be detected in the gas phase. The overestimation of the gaseous fraction by ELPOS might cause an overestimation of $\mathrm{B}[\mathrm{a}] \mathrm{P}$ and Ind removal by degradation.

The estimated CTD of all compounds was directly proportional to wind speed (Figure 3D). The half-life of the volatile compounds in air was another highly sensitive parameter, whereas the particle-bound substances were more sensitive to precipitation and the height of the air compartment. The dry particle deposition velocity only substantially influenced the p-PAHs and particles. The sensitivity of the CTD against changes in temperature was $\leq 0.21$ and similar regarding all compounds other than $\mathrm{B}[\mathrm{b}] \mathrm{F}$ and particles.

\subsubsection{Model Comparison}

When the same degradation half-lives and temperature-adjusted partition coefficients were used in both models, i.e., the internal temperature correction of ELPOS was not used, the CTDs calculated by both models agreed reasonably well (Figure 4A) and were significantly correlated $\left(R^{2}=0.92\right.$, $p<0.00015)$. 
Figure 3. Characteristic Travel Distance (CTD) of selected PAHs normalized to the CTD of particles estimated with (A) The Tool; and (C) ELPOS for the three temperature scenarios, and sensitivity of the CTD at $4{ }^{\circ} \mathrm{C}$ to the model input parameters estimated with (B) The Tool; and (D) ELPOS (note: data not presented here available in Supporting Material, Tables S11 and S12; the lines in sub-figures B and D are shown for visual support in identifying the individual parameters). The assignment of PAHs to groups according to their atmospheric partition behavior is indicated in brackets. depovelo $=$ dry particle deposition velocity.
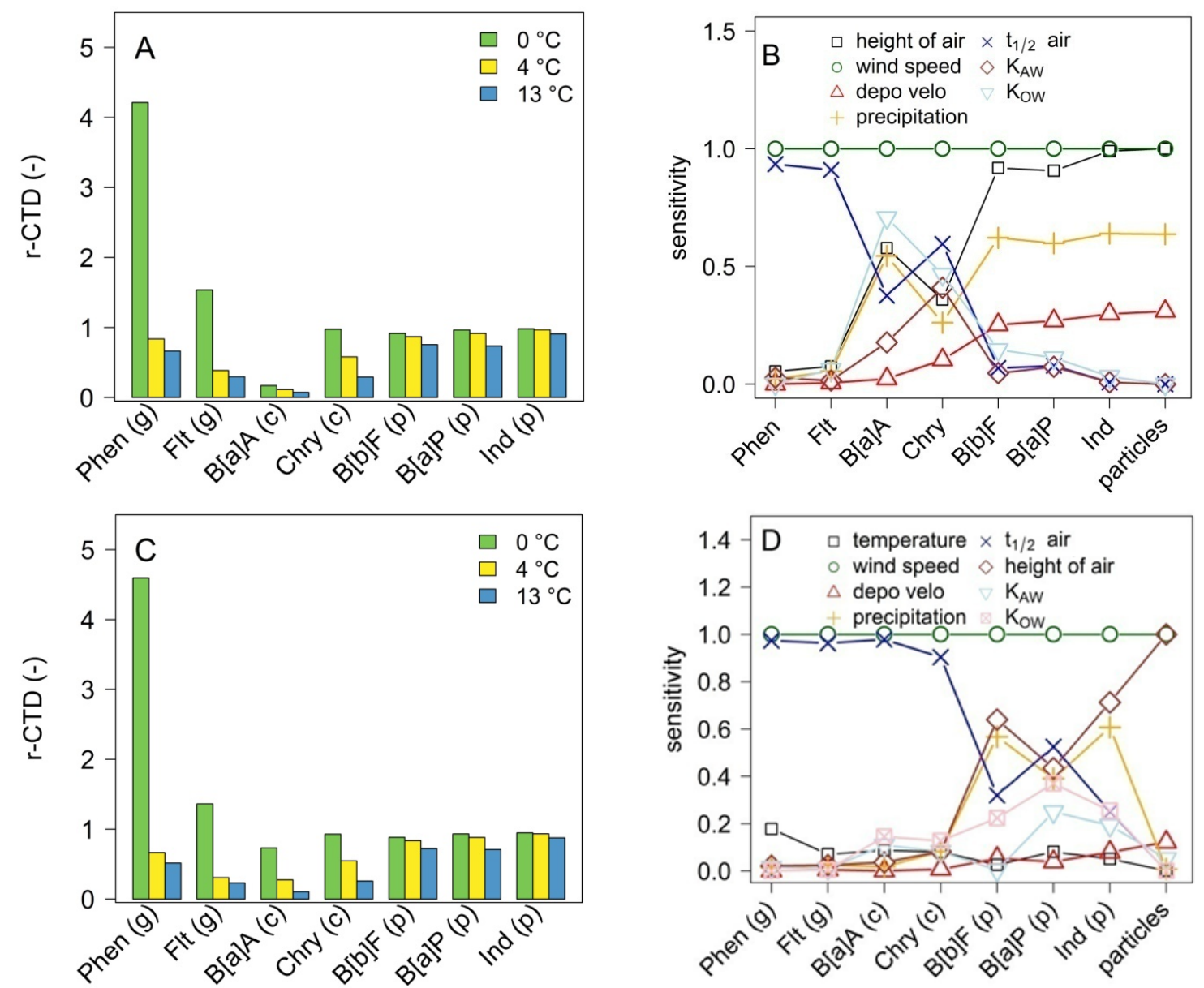

However, most ELPOS-CTDs were above the 1:1-line, i.e., ELPOS systematically estimated longer CTDs than The Tool. CTDs normalized to that of the particles agreed very well between both models, with all compounds falling close to the 1:1-line (Figure 4B). Clearly, normalization eliminates systematic difference between the models. The agreement for $\mathrm{p}$ - and c-PAHs was even better after normalizing the CTDs to that of Ind (Figure 4C).

When the in-built temperature-adjustment of ELPOS was used, the agreement between the models diminished. On the one hand, a substantial increase of CTDs calculated using ELPOS was observed for Phen and Flt (Figure 4A) with the temperature adjustment. This finding was not surprising as the temperature-adjustment of the atmospheric half-lives in ELPOS substantially increased the half-lives with decreasing temperatures (for $0{ }^{\circ} \mathrm{C}$ the increase was $200 \%$, see Table S6), while the half-lives were not adjusted in The Tool. Moreover, the sensitivity of the two gas-phase PAHs Phen and Flt against 
changes in half-lives was high in both models (Figure 3B,D). For this reason, these two PAHs should indeed be most affected by the discrepancy of the degradation rates in the gas phase. ELPOS applies a default activation energy of $30 \mathrm{~kJ} \cdot \mathrm{mol}^{-1}$ for the temperature adjustment of the atmospheric degradation rate for all compounds. Using $10 \mathrm{~kJ} \cdot \mathrm{mol}^{-1}$ instead, the increase of $t_{1 / 2}$ of Phen in air at lower temperatures was reduced by $46 \%$. The experimentally determined activation energy of Phen and Flt is less than $10 \mathrm{~kJ} \cdot \mathrm{mol}^{-1}$ [37]. Therefore, the temperature adjustment in ELPOS might underestimate atmospheric degradation of PAHs at low temperature. On the other hand, the CTDs of the less volatile PAHs generally decreased when the implemented temperature adjustment was used. This is because the default temperature dependence of the partitioning coefficients implemented in ELPOS was larger than the dependence obtained manually, i.e., the PAHs partitioned more into the particulate phase in ELPOS than this was the case for the adjusted input values we used in The Tool.

Figure 4. Comparison of characteristic travel distances predicted by The Tool and ELPOS for the average temperature scenario $\left(4^{\circ} \mathrm{C}\right)$. Results from ELPOS were obtained both with the built-in temperature correction of partition coefficients and reaction rates (ELPOS auto T-adj) and with the parameters that were temperature-adjusted manually as in The Tool (ELPOS man. T-adj). (A) Absolute CTDs; (B) CTDs relative to the particle-CTD; (C) CTDs relative to Ind. The 1:1-line is shown as dotted line.
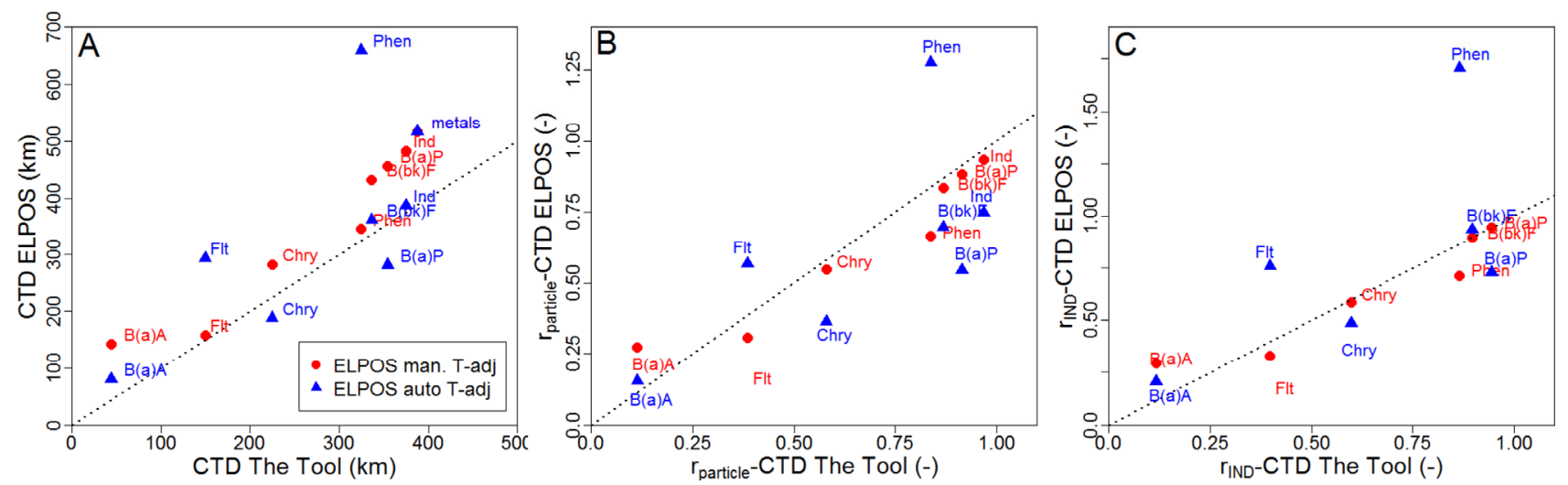

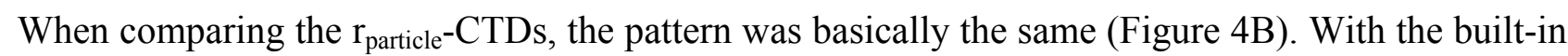
adjustment, however, the $\mathrm{r}_{\text {particle}}$-CTDs of the less volatile PAHs calculated by ELPOS were now consistently smaller than those with the manual temperature adjustment. Overall, the major discrepancies between the two models can be seen for the more volatile compounds, while the

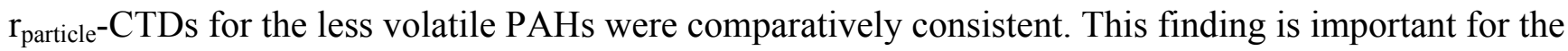
comparison with measured ETDs, as these are only available for the less volatile compounds and thus for compounds with a lower overall deviation between the two models.

The sensitivity of both models against changes in the individual input parameters was similar for the g-PAHs, and only wind speed and $t_{1 / 2}$ in air had a strong influence. However, while this half-life still strongly influenced the CTD of the c-PAHs in ELPOS, i.e., sensitivity was close to 1, the influence was substantially lower in The Tool (Figure 3B,D). This result can be attributed to a substantially lower fraction of $\mathrm{B}[\mathrm{a}] \mathrm{A}$ and Chry in the atmospheric gas phase in The Tool (20\%) than in ELPOS (84\%) (see Supporting Material for details). As Su et al. [14] found them to be $80 \%$ in the gas phase in summer and $40 \%$ in winter, The Tool obviously under-predicts the gaseous fraction. 
The sensitivity of these compounds against $K_{\mathrm{AW}}$ in The Tool was higher than that of the other PAHs and than found in ELPOS. This observation is most likely due to its sensitivity to $K_{\mathrm{OA}}$, which was governing the gas/particle partitioning. Sensitivity to $\mathrm{K}_{\mathrm{OA}}$, which was calculated from the $K_{\mathrm{AW}}$, thus indicates which compounds primarily partition from gas to particle phase and are crucially affected by the partitioning coefficient. In the Tool the c-PAHs, whereas in ELPOS the p-PAHs were affected. For the predominantly particle-bound PAHs, processes determining the fate of atmospheric particles, such as precipitation and dry particle deposition velocity, became more influential in both models, although the dry deposition velocity was more influential in The Tool.

\subsubsection{Comparison of CTDs and ETDs}

The absolute ETDs of PAHs derived from the peat transect were between 281 and $321 \mathrm{~km}$, whereas the absolute CTDs with regional settings were between 44 and $480 \mathrm{~km}$ (average temperature scenario, $\left.4{ }^{\circ} \mathrm{C}\right)$. The latter are comparable to the CTD calculated for aldrin ( 200 km (The Tool) and $95 \mathrm{~km}$ (ELPOS), using the input values implemented in both models), a pesticide banned by the Stockholm Convention on Persistent Organic Pollutants [48], and which has-compared to most banned substances - a relatively low LRTP [49].

The direct comparison between measured ETDs and calculated CTDs was impeded by the fact that the Greater Sudbury area is a point source on the regional scale. Even without any degradation and deposition, the PAH concentrations would thus decline with distance from the source because of radial dilution. Such a dilution is not implemented into either model, and instead a line source and wind that is blowing in a constant direction are assumed. However, by normalizing the measured and calculated transport distances to a common reference, i.e., non-reactive particles, the comparison between measurements and model becomes feasible as the effects of radial dilution, wind speed, and a changing wind direction are eliminated. Moreover, when using a particle-bound substance as a reference, differences in parameters that affect the deposition of atmospheric particles between the real environment and the model settings are eliminated as well, and the relative comparison of a given set of compounds in terms of atmospheric travel distance is possible.

As both models are intended to calculate the transport potential and to compare compounds relative to each other, rather than to reproduce real transport distances in the environment, it is more meaningful to compare relative CTDs with relative ETDs instead of absolute values. This comparison

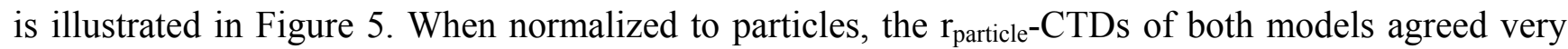

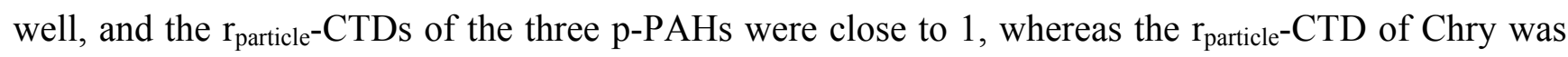
substantially lower. However, the measured $r_{\text {metal }}$-ETD for all four compounds was much higher and around 1.5 for all compounds. Thus, the agreement between measured and modeled relative transport distances was not very good. This outcome might be attributed to a different atmospheric behavior of the particles that metals and PAHs are associated with, or to some inaccuracy of the estimated particle-CTDs. Although it is very likely that PAHs and metals in historic samples shared the same dominant source in the Greater Sudbury area, they might be associated with different aerosol size classes. The particles contained differ in their atmospheric transport behavior and metals associated with somewhat larger particles than PAHs may consequently be removed from the atmosphere faster. Alternatively, PAHs might not be as reactive as the models assume. The importance of these factors 


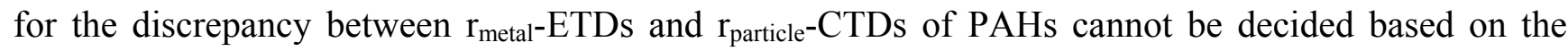
currently available knowledge.

Figure 5. Comparison of relative ETDs and CTDs of PAHs at $4^{\circ} \mathrm{C}$ ((left): relative to metals (ETD) and particles (CTD); (right): relative to Ind).
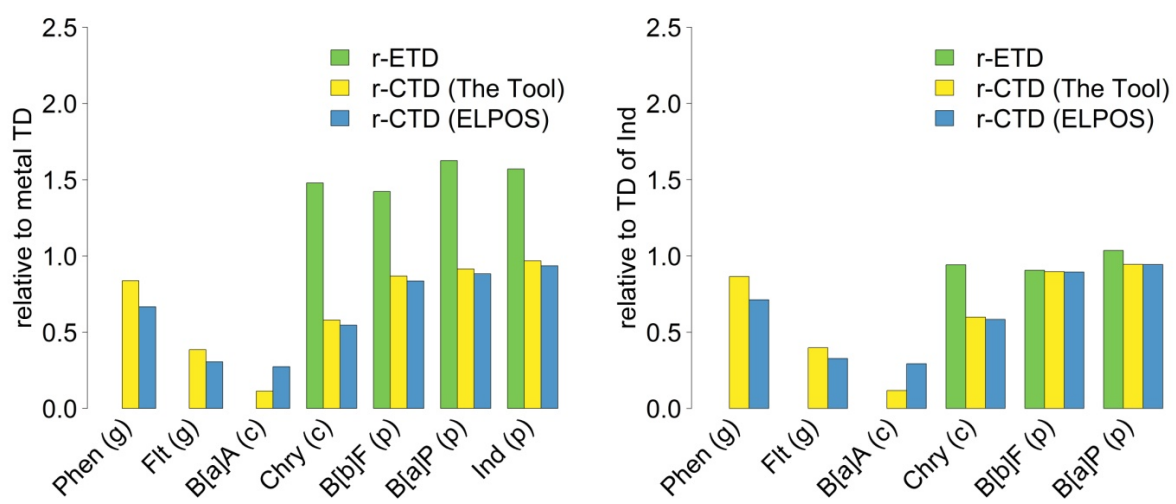

To further reduce uncertainty, the CTD of PAHs can be normalized to the travel distance of Ind (or any other of the p-PAHs) instead of metals (Figures 4C and 5B), thereby referencing the transport distance to a compound with identical emission behavior and that is association with particle of similar size. This procedure yielded a very good agreement between measurement and model for $\mathrm{B}[\mathrm{b}] \mathrm{F}$ and $\mathrm{B}[\mathrm{a}] \mathrm{P}$, while the estimated $\mathrm{r}_{\text {Ind }}$-CTDs for Chrysene (ELPOS: 0.38; The Tool: 0.42) were much lower than the actually measured $\mathrm{r}_{\text {Ind }}$-ETD (0.94).

The finding that the measured r-ETD of Chry was almost identical to the r-ETDs of the other three PAHs was unexpected, as Chry is substantially more volatile (see Supporting Material, Table S4 for partition coefficients). Both Chry and Ind have similar atmospheric half-lives but Chry is the compound with the higher volatility and it should thus be removed faster if the assumption is correct that particle-bound PAHs are degraded much slower than gas phase PAHs [29]. The discrepancy between r-ETD and r-CTD can have two reasons: (i) The volatility of Chry might be overestimated in the models which assume an ideal partitioning behavior of PAHs. For $0{ }^{\circ} \mathrm{C}$ ELPOS assumed $24 \%$ of Chry to be bound to particles, while Su et al. [14] found about $60 \%$ of Chry bound to particles in winter. Harner and Bidleman [50] supposed that PAHs might be bound within particles during their formation in combustion processes and thus might be non-exchangeable with the atmosphere. Moreover, PAHs initially present on the surface of particles may become less accessible for reactions, partitioning and volatilization due to a coating of the particles by secondary aerosol components [17,31]; (ii) The actual atmospheric half-life of Chry might be much longer than that used for estimating its CTD. However, in order to reach a $r_{\text {Ind }}-C T D$ equal to the $r_{\text {Ind }}$-ETD, in ELPOS a nearly 10 -fold increase in $t_{1 / 2}$ would be necessary, while it is even impossible to reach such a CTD in The Tool by increasing the atmospheric half-life.

Two previous studies aimed at comparing measured and calculated transport distances of organic pollutants. Shen et al. [10] found a good agreement between ETDs of pesticides with high LRTP determined from latitudinal gradients of air concentrations and CTDs calculated by ELPOS and two other models. In contrast, ETDs for pesticides derived from water concentrations in North American lakes were tenfold higher than the CTDs calculated by four models. This difference could be 
reduced by lowering the hydroxyl radical concentration and introducing dry weather conditions [11]. Unfortunately, both studies did not measure metals or other predominantly particle-bound reference substances to allow for the calculation of relative travel distances.

\section{Conclusions}

In this study the comparison between modeled and measured transport distances was limited to only a few compounds, as the peat profiles did not reveal statistically significant ETDs for more PAH congeners. Keeping this in mind, several general conclusions can be drawn:

- The absolute CTDs of PAHs estimated with the two models agreed reasonably well for predominantly particle-bound congeners, while discrepancies were observed for the more volatile congeners (Figure 4). This could be attributed to the temperature-adjustment of input parameters (in particular, $K_{\mathrm{AW}}$ and half-life in air) in ELPOS, which relies on generic assumptions, most importantly with respect to the temperature dependence of the atmospheric degradation half-life. Since the CTDs of rather volatile compounds in both models are highly sensitive to the half-life in air (Figure 3), the quality of the predictions would improve with better data on the temperature dependence of the atmospheric degradation half-lives of PAHs and the implementation of this dependence in both models.

- Peat archives sampled from bogs at variable distance from a single dominant point source can be used to experimentally determine travel distances of pollutants.

- Particles deposit onto peat and, therefore, peat archives can provide information about the relative transport distances of particle-bound compounds. Most other passive samplers collect only compounds in the gas phase.

- Data from peat archives are suitable to experimentally evaluate predicted CTDs of PAHs if data are normalized to a reference compound with similar behavior, even if the source characteristics (point vs. linear source) differ between model and reality. However, in the present study, the results from the peat archive limited the number of compounds available for such an evaluation. This conclusion might also apply to other non-polar atmospheric contaminants measured in peat archives.

- The underestimation of the $\mathrm{r}_{\text {particle}}$-CTD of Chry might be due to a "non-ideal" partitioning behavior, i.e., Chry associated to aerosol particles might not freely partition to the gas phase. More information on such processes is needed to verify this hypothesis experimentally. Such a process could also apply to other contaminants that are already particle-bound during their emission. Compounds predominantly emitted as gaseous compounds would be less affected.

\section{Acknowledgments}

The authors thank the German Research Foundation (DFG; project RA 896/6-1) and the German Academic Exchange Service (DAAD; project 50021462) for financial support, and the administration of Ontario Parks for permission to sample in Algonquin Provincial Park. We also thank B. Planer-Friedrich for the metal analyses, as well as J. Klasmeier and C. Ehling for support concerning 
ELPOS. We thank three anonymous reviewers for constructive comments on an earlier version of the manuscript.

\section{Author Contributions}

All authors contributed to study design, data interpretation, and writing of the manuscript. Sabine Thuens performed most of the research and was lead author of this manuscript. Christian Blodau contributed to sampling and interpretation of peat data. Frank Wania contributed to the model-related aspects of the research. Michael Radke contributed to sampling and sample analysis and data interpretation.

\section{Conflicts of Interest}

The authors declare no conflict of interest.

\section{References}

1. Van Pul, W.A.J.; de Leeuw, F.A.A.M.; van Jaarsveld, J.A.; van der Gaag, M.A.; Sliggers, C.J. The potential for long-range transboundary atmospheric transport. Chemosphere 1998, 37, 113-141.

2. Scheringer, M. Persistence and spatial range as endpoints of an exposure-based assessment of organic chemicals. Environ. Sci. Technol. 1996, 30, 1652-1659.

3. Rodan, B.D.; Pennington, D.W.; Eckley, N.; Boethling, R.S. Screening for persistent organic pollutants: Techniques to provide a scientific basis for pops criteria in international negotiations. Environ. Sci. Technol. 1999, 33, 3482-3488.

4. Bennett, D.H.; McKone, T.E.; Matthies, M.; Kastenberg, W.E. General formulation of characteristic travel distance for semivolatile organic chemicals in a multimedia environment. Environ. Sci. Technol. 1998, 32, 4023-4030.

5. Beyer, A.; Matthies, M. Criteria for Atmospheric Long-Range Transport Potential and Persistence of Pesticides and Industrial Chemicals; Technical Report FKZ 299265 402; German Federal Environmental Agency: Berlin, Germany, 2001.

6. Scheringer, M.; MacLeod, M.; Wegmann, F. The OECD $\mathrm{P}_{\mathrm{OV}}$ and LRTP Screening Tool, Version 2.0. Available online: http://www.sust-chem.ethz.ch/docs/Tool2_0_Manual.pdf (accessed on 20 July 2011).

7. Wegmann, F.; Cavin, L.; MacLeod, M.; Scheringer, M.; Hungerbuehler, K. The OECD software tool for screening chemicals for persistence and long-range transport potential. Environ. Modell. Softw. 2009, 24, 228-237.

8. Klasmeier, J.; Matthies, M.; Macleod, M.; Fenner, K.; Scheringer, M.; Stroebe, M.; Le Gall, A.C.; McKone, T.; van De Meent, D.; Wania, F. Application of multimedia models for screening assessment of long-range transport potential and overall persistence. Environ. Sci. Technol. 2005, $40,53-60$. 
9. Fenner, K.; Scheringer, M.; Hungerbuhler, K. Prediction of overall persistence and long-range transport potential with multimedia fate models: Robustness and sensitivity of results. Environ. Pollut. 2004, 128, 189-204.

10. Shen, L.; Wania, F.; Lei, Y.D.; Teixeira, C.; Muir, D.C.G.; Bidleman, T.F. Atmospheric distribution and long-range transport behavior of organochlorine pesticides in North America. Environ. Sci. Technol. 2004, 39, 409-420.

11. Muir, D.C.G.; Teixeira, C.; Wania, F. Empirical and modeling evidence of regional atmospheric transport of current-use pesticides. Environ. Toxicol. Chem. 2004, 23, 2421-2432.

12. Björseth, A.; Lunde, G.; Lindskog, A. Long-range transport of polycyclic aromatic hydrocarbons. Atmos. Environ. 1979, 13, 45-53.

13. Yamasaki, H.; Kuwata, K.; Miyamoto, H. Effects of ambient temperature on aspects of airborne polycyclic aromatic hydrocarbons. Environ. Sci. Technol. 1982, 16, 189-194.

14. Su, Y.; Lei, Y.D.; Wania, F.; Shoeib, M.; Harner, T. Regressing gas/particle partitioning data for polycyclic aromatic hydrocarbons. Environ. Sci. Technol. 2006, 40, 3558-3564.

15. Steinnes, E.; Allen, R.O.; Petersen, H.M.; Rambæk, J.P.; Varskog, P. Evidence of large scale heavy-metal contamination of natural surface soils in Norway from long-range atmospheric transport. Sci. Total Environ. 1997, 205, 255-266.

16. Chan, W.H.; vet, R.J.; Ro, C.-U.; Tang, A.J.S.; Lusis, M.A. Impact of INCO smelter emissions on wet and dry deposition in the Sudbury area. Atmos. Environ. 1984, 18, 1001-1008.

17. Ravindra, K.; Sokhi, R.; van Grieken, R. Atmospheric polycyclic aromatic hydrocarbons: Source attribution, emission factors and regulation. Atmos. Environ. 2008, 42, 2895-2921.

18. Venkataraman, C.; Friedlander, S.K. Size distributions of polycyclic aromatic hydrocarbons and elemental carbon. 2. Ambient measurements and effects of atmospheric processes. Environ. Sci. Technol. 1994, 28, 563-572.

19. Biester, H.; Bindler, R.; Martinez-Cortizas, A.; Engstrom, D.R. Modeling the past atmospheric deposition of mercury using natural archives. Environ. Sci. Technol. 2007, 41, 4851-4860.

20. Dreyer, A.; Radke, M.; Turunen, J.; Blodau, C. Long-term change of polycyclic aromatic hydrocarbon deposition to peatlands of eastern Canada. Environ. Sci. Technol. 2005, 39, 3918-3924.

21. Shotyk, W. Peat bog archives of atmospheric metal deposition: Geochemical evaluation of peat profiles, natural variations in metal concentrations, and metal enrichment factors. Environ. Rev. 1996, 4, 149-183.

22. Thuens, S.; Blodau, C.; Radke, M. How suitable are peat cores to study historical deposition of PAHs? Sci. Total Environ. 2013, 450-451, 271-279.

23. Sehmel, G.A. Particle and gas dry deposition: A review. Atmos. Environ. 1980, 14, 983-1011.

24. Ma, Y.-G.; Lei, Y.D.; Xiao, H.; Wania, F.; Wang, W.-H. Critical review and recommended values for the physical-chemical property data of 15 polycyclic aromatic hydrocarbons at $25{ }^{\circ} \mathrm{C}$. J. Chem. Eng. Data 2009, 55, 819-825.

25. Bauer, M.; Fulda, B.; Blodau, C. Groundwater derived arsenic in high carbonate wetland soils: Sources, sinks, and mobility. Sci. Total Environ. 2008, 401, 109-120. 
26. Appleby, P.G.; Oldfield, F. The calculation of lead-210 dates assuming a constant rate of supply of unsupported ${ }^{210} \mathrm{~Pb}$ to the sediment. CATENA 1978, 5, 1-8.

27. Turetsky, M.R.; Manning, S.W.; Wieder, R.K. Dating recent peat deposits. Wetlands 2004, 24, 324-356.

28. Institute for Statistics and Mathematics of the WU Wien, R Version 2.13.1. Available online: http://www.r-project.org/ (accessed on 20 July 2011).

29. Beyer, A.; Wania, F.; Gouin, T.; Mackay, D.; Matthies, M. Temperature dependence of the characteristic travel distance. Environ. Sci. Technol. 2003, 37, 766-771.

30. Mackay, D. Multimedia Environmental Models-The Fugacity Approach, 2nd ed.; Lewis Publishers: Boca Raton, FL, USA, 2001.

31. Zhou, S.; Lee, A.K.Y.; McWhinney, R.D.; Abbatt, J.P.D. Burial effects of organic coatings on the heterogeneous reactivity of particle-borne benzo[a]pyrene (BaP) toward ozone. J. Phys. Chem. A 2012, 116, 7050-7056.

32. Environment Canada. Canadian Climate Normals for North Bay -A, WMO ID: 71731, Period 1971-2000. Available online: http://www.climate.weatheroffice.gc.ca (accessed on 20 July 2011).

33. Bronner, G.; Goss, K.-U. Predicting sorption of pesticides and other multifunctional organic chemicals to soil organic carbon. Environ. Sci. Technol. 2010, 45, 1313-1319.

34. Advanced Chemistry Development, Inc. ACD/Absolv. Available online: http://www.acdlabs.com/ products/percepta/predictors/absolv/ (accessed on 20 July 2011).

35. Goss, K.U. Prediction of the temperature dependency of Henry's law constant using poly-parameter linear free energy relationships. Chemosphere 2006, 64, 1369-1374.

36. Goss, K.-U.; Schwarzenbach, R.P. Empirical prediction of heats of vaporization and heats of adsorption of organic compounds. Environ. Sci. Technol. 1999, 33, 3390-3393.

37. Brubaker, W.W.; Hites, R.A. OH reaction kinetics of polycyclic aromatic hydrocarbons and polychlorinated dibenzo-p-dioxins and dibenzofurans. J. Phys. Chem. A 1998, 102, 915-921.

38. Spivakovsky, C.M.; Logan, J.A.; Montzka, S.A.; Balkanski, Y.J.; Foreman-Fowler, M.; Jones, D.B.A.; Horowitz, L.W.; Fusco, A.C.; Brenninkmeijer, C.A.M.; Prather, M.J.; et al. Three-dimensional climatological distribution of tropospheric $\mathrm{OH}$ : Update and evaluation. J. Geophys. Res. 2000, 105, 8931-8980.

39. USNO. Duration of daylight/darkness table for one year. Available online: http://aa.usno.navy.mil/data/docs/Dur_OneYear.php (accessed on 27 March 2014).

40. EPA. Estimation Program Interface (EPI) Suite. Available online: http://www.epa.gov/ opptintr/exposure/pubs/episuite.htm (accessed on 20 July 2011).

41. Wania, F.; Dugani, C.B. Assessing the long-range transport potential of polybrominated diphenyl ethers: A comparison of four multimedia models. Environ. Toxicol. Chem. 2003, 22, 1252-1261.

42. SARA. Volume I-Chapter 3: Historical Review of Air Emissions from the Smelting Operations. Available online: http://www.sudburysoilsstudy.com/EN/media/volume_I.asp (accessed on 3 July 2012).

43. Freedman, B.; Hutchinson, T.C. Pollutant inputs from the atmosphere and accumulations in soils and vegetation near a nickel-copper smelter at Sudbury, Ontario, Canada. Can. J. Bot. 1980, 58, 108-132. 
44. Nieboer, E.; Ahmed, H.M.; Puckett, K.J.; Richardson, D.H.S. Heavy metal content of lichens in relation to distance from a nickel smelter in Sudbury, Ontario. Lichenologist 1972, 5, 292-304.

45. Kettles, I.M.; Bonham-Carter, G.F. Modelling dispersal of metals from a copper smelter at Rouyn-Noranda (Quebec, Canada) using peatland data. Geochemistry 2002, 2, 99-110.

46. Allen, A.G.; Nemitz, E.; Shi, J.P.; Harrison, R.M.; Greenwood, J.C. Size distributions of trace metals in atmospheric aerosols in the United Kingdom. Atmos. Environ. 2001, 35, 4581-4591.

47. Caffrey, P.F.; Ondov, J.M.; Zufall, M.J.; Davidson, C.I. Determination of size-dependent dry particle deposition velocities with multiple intrinsic elemental tracers. Environ. Sci. Technol. 1998, 32, 1615-1622.

48. UNEP. Final Act of the Conference of Plenipotentaries on the Stockholm Convention on Persistent Organic Pollutants; United Nations Environment Program: Stockholm, Sweden, 2001.

49. Beyer, A.; Mackay, D.; Matthies, M.; Wania, F.; Webster, E. Assessing long-range transport potential of persistent organic pollutants. Environ. Sci. Technol. 2000, 34, 699-703.

50. Harner, T.; Bidleman, T.F. Octanol-air partition coefficient for describing particle/gas partitioning of aromatic compounds in urban air. Environ. Sci. Technol. 1998, 32, 1494-1502.

(C) 2014 by the authors; licensee MDPI, Basel, Switzerland. This article is an open access article distributed under the terms and conditions of the Creative Commons Attribution license (http://creativecommons.org/licenses/by/3.0/). 